\title{
Progressive Modelling of the Gravity-induced Landslide Using the Local Dynamic Strength Reduction Method
}

\author{
CHEN Guo-qing*, HUANG Run-qiu, XU Qiang, LI Tian-bin, ZHU Ming-lei \\ State Key Laboratory of Geohazard Prevention and Geoenvironment Protection, Chengdu University of Technology, \\ Chengdu 610059, China \\ *Corresponding author, e-mail: chgq1982@126.com
}

(C) Science Press and Institute of Mountain Hazards and Environment, CAS and Springer-Verlag Berlin Heidelberg 2013

\begin{abstract}
The failure of slope is a progressive process, and the whole sliding surface is caused by the gradual softening of soil strength of the potential sliding surface. From this viewpoint, a local dynamic strength reduction method is proposed to capture the progressive failure of slope. This method can calculate the warning deformation of landslide in this study. Only strength parameters of the yielded zone of landslide will be reduced by using the method. Through continuous local reduction of the strength parameters of the yielded zone, the potential sliding surface developed gradually and evolved to breakthrough finally. The result shows that the proposed method can simulate the progressive failure of slope truly. The yielded zone and deformation of landslide obtained by the method are smaller than those of overall strength reduction method. The warning deformation of landslide can be obtained by using the local dynamic strength reduction method which is based on the softening characteristics of the sliding surface.
\end{abstract}

Keywords: Landslide; Local dynamic reduction; Warning deformation; Strength softening; Progressive failure

\section{Introduction}

Landslides pose great threat to society; therefore, landslide forecast has been at the

Received: 12 April 2012

Accepted: 20 September2012 forefront of landslide research (Evans et al. 2002). Current landslide forecast is based on empirical formula (e.g., Saito 1965), linear forecast (Rennie 2010), nonlinear forecast (Feng et al 2010; Li et al. 2012), phenomenon forecast (Xu et al. 2008), GPS forecast (Malet et al. 2002), and monitoring forecast (Giovanni et al. 2011). Although many landslide forecast models and criteria have been proposed, landslide forecast practice has shown that the existing forecast models can not accurately forecast landslide deformations. In fact, landslide deformation is a progressive process (Petley et al. 2005; Eberhardt et al. 2008; Leroueil et al. 2012); therefore, forecast models that do not adequately account for the progressive slope deformation can not forecast landslide accurately and reliably.

Given the wide development of numerical applications available today, numerical modelling is used routinely as well as finite element method for slope failure (Griffiths et al. 1999; Zheng et al. 2008). Especially, the strength reduction method plays an important role in the slope stability analysis (Matsui et al. 1992; Dawson et al. 1999; Eberhardt 2008; Zheng et al. 2009). However, the reduction range is controversial in the strength reduction method (Zheng et al. 2008; Yang et al. 2010). If the strength of whole slope is reduced, the slope deformation may be greater than the actual deformation, and the yielded region may be overestimated. Therefore, the strength reduction method also can not capture progressive failure and deformation process of landslide. 
Therefore, local dynamic strength reduction method was proposed to simulate the progressive failure of the gravity-induced landslides based on the softening of the strength of the sliding surface. The mechanical parameters of yielded element are reduced gradually in the process of computation reduction, making the slope body gradually fail and the potential sliding surface is searched out automatically. Example shows that the proposed method can simulate the progressive failure of slope and calculate the early warning deformation of landslide.

\section{Numerical Modelling of Failure Process}

\subsection{Basic theory of the progressive modelling}

Gravity-induced landslides are often triggered by excavation operations. Gravitational instability and excavation damage cause a progressive softening (strength reduction) of landslide (Chemenda et al. 2009). At first a slope will undergo micro-cracking when the toe of the slope is failure, then the strength of the material is weakened. This process would cause irreversible deformation and stress concentration, then shear stress is transferred to the neighbouring region where further micro-cracking will take place and further strain will develop (Petley et al. 2005). This continuous process reduces the shear strength of the shear zone, and eventually final failure begins when the failure initiation line is reached.

Progressive failure of slope can be illustrated by Figure 1 (Leroueil et al. 2012). The process is as follows: at point 3 , the shear stress is at its peak

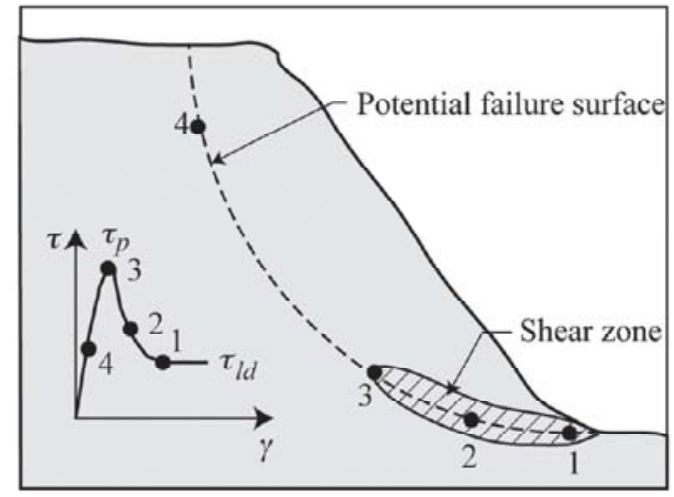

Figure 1 Progressive failure along a potential slip surface (Leroueil 2012) $\left(\tau_{\mathrm{p}}\right)$; the shear stress is beyond the peak at points 2 and 1 , and may have reached the large deformation strength $\left(\tau_{1 \mathrm{~d}}\right)$ along part of the failure surface (e.g., at point 1); at point 4 , the shear stress is well below the peak shear strength. The progressive failure will continue to progress from point 3 towards point 4 , and eventually the whole sliding surface will be mobilized.

So the softening of strength is the main reason that causes landslide. Shear strength of failure region must be reduced from peak to residual values in the numerical modelling, and the failure surface can develop gradually.

\subsection{Numerical modelling method}

According to the above characteristics of landslide, local dynamic reduction method has been proposed to simulate the progressive failure of slope based on the softening of the sliding surface. The essential idea of this method is shown in Figure 2.

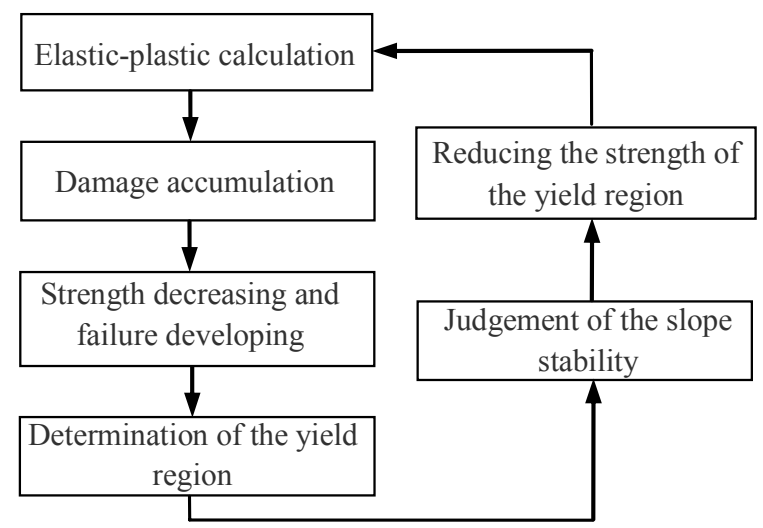

Figure 2 Calculation process of the local dynamic reduction method

First, the local yielded region (element) which first appears in the slope should be determined. The overall strength reduction method or overload method can be used to determine the yielded region that appeared first. (Zheng et al. 2009; Eberhardt 2008). The overall strength parameters of the slope are reduced. If no element damage occurs, the reduction factor is increased continuously, and then the elastic-plastic mechanical calculation is performed until the local yielded element appears. If the failure is caused by excavation, elastic-plastic calculation of the slope 
can determine the yielded region after the excavation.

Mohr-Coulomb criterion and tensile strength are used as failure criterion:

$$
\begin{gathered}
F^{s}=\frac{1}{3} I_{1} \sin \phi-c \cos \phi+\sqrt{J_{2}}\left(\cos \theta_{\sigma}+\frac{\sin \theta_{\sigma} \sin \phi}{\sqrt{3}}\right)=0 \\
F^{t}=\sigma_{3}-\sigma_{t}=0
\end{gathered}
$$

where $I_{1}$ and $J_{2}$ are the first invariant of stress tensor and second invariant of stress deviator, respectively, $\sigma_{3}$ is the minor principal stress, and $\sigma_{t}$ is the tensile strength.

Then, according to Equation 1 and Equation 2, the yielded regions of slope are determined in the process of progressive failure. Because the strength of the yielded elements is softened and weakened from peak to residual values after cracking, the strength parameters of the yielded regions must be reduced. The softening degree of the yielded element is followed by Equation 3:

$$
\left.\begin{array}{c}
c_{y}=\alpha c \\
\varphi_{y}=\arctan (\alpha \tan \varphi)
\end{array}\right\}
$$

where $C$ is cohesion, $\phi$ is internal friction angle, $c_{y}$ is cohesion of the yielded element, $\varphi_{y}$ is internal friction angle of the yielded element, and $\alpha$ is the softening coefficient.

The strength parameters are determined by using the softening coefficient $(\alpha)$, and the new parameters are put into the elastic-plastic calculation. A progressive homogeneous reduction of the cohesion was applied to destabilize the slope, and this method is considered to be the principle for the stability analysis of gravity-induced landslides (Martel et al. 2003; Eberhardt 2004; Eberhardt 2008; Chemenda et al. 2009). This assumption is also made in most geotechnical applications and it was adopted in this study.

Last, the yielded area of slope continues to expand gradually with the increase of reduction calculation (Figure 2). At the same time, limit equilibrium method is also used to evaluate the stability of the yielded slope. The safety factor $\left(F_{\mathrm{s}}\right)$ can be obtained by the limit equilibrium method, and $F_{\mathrm{s}}$ is dynamically changed in the process of progressive failure.

It is important to emphasize that only the mechanical parameters of the increased new yielded elements are reduced. The increased new yielded elements are obtained in the last elasticplastic mechanical calculation, and the number of yielded elements will increase in the next mechanical calculation. So the reduced zones of slope are not kept constant but dynamic.

The local dynamic reduction method based on the softening of the sliding surface is not only suitable for homogeneous slopes but also for the heterogeneous slopes. Now, two case studies are carried out to verify the validity of the method. One case study is a homogeneous slope, another is a heterogeneous landslide.

\section{Case Study of Homogeneous Slope}

In this case study, the local dynamic and overall strengthreduction methods are used to calculate the progressive failure of a homogeneous slope, so the rationality of the local dynamic method can be analyzed.

\subsection{Local dynamic reduction method}

A homogeneous slope was analyzed as an example. The basic shape and grid of slope are shown in Figure 3, each grid size is $0.5 \mathrm{~m}$, and the grid number is 1,360 . The height of the slope is 10 $\mathrm{m}$, and the unit weight of soil is $20 \mathrm{kN} / \mathrm{m}^{3}$. The cohesion is $20 \mathrm{kPa}$, and the internal friction angle is $20^{\circ}$. The bulk modulus is $800 \mathrm{MPa}$, shear modulus is $30 \mathrm{MPa}$, and the slope angle is $45^{\circ}$.

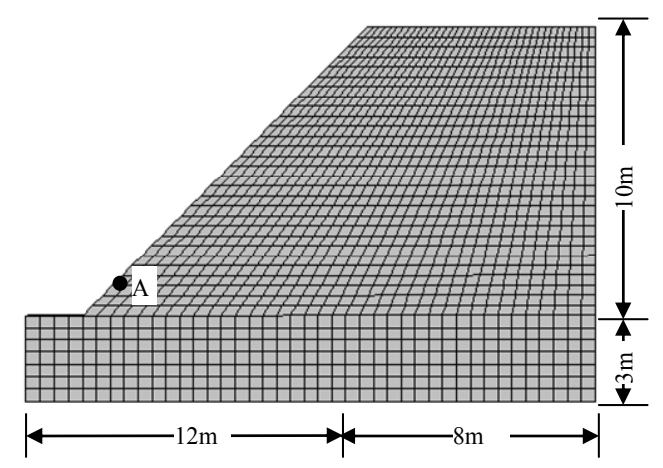

Figure 3 Mesh of the homogeneous soil slope

The initial and boundary conditions are as follows: the stress field of the slope is the selfweight stress field, and it is the initial condition of 
the model. The left and right borders are horizontal displacement constraints and the bottom border is fixed in all directions.

The study was modeled by using the $\mathrm{FLAC}_{3} \mathrm{D}$ software. The deformation mutation characteristics of monitoring points were chosen as the instability criterion of slope in the reduction method. The deformation will grow rapidly when the strength is reduced to a certain degree. Therefore, the sudden acceleration of the displacement means the failure of slope.

According to the reduction step in Figure 2, the first elastic-plastic mechanical calculation shows that there are yielded elements at the toe of the slope (Figure 4).

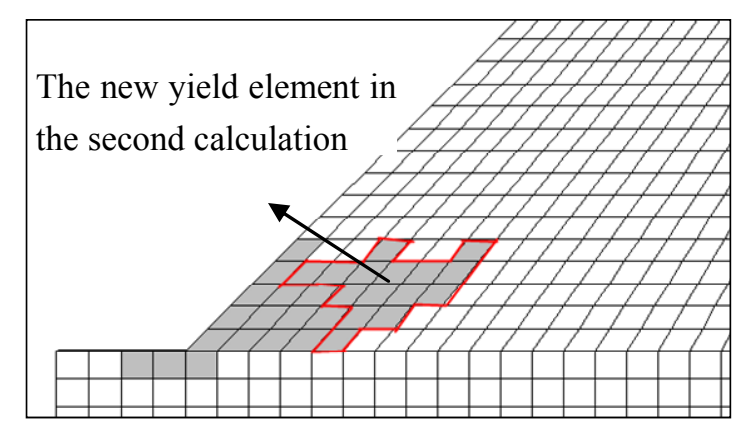

Figure 4 Yielded zone of slope after the 2nd elasticplastic calculation

Based on the idea of strength softening, strength parameter of the yielded elements was reduced. Only the cohesion $C$ was reduced to $0.6 C$ while the internal friction angle is constant. The elastic-plastic calculation is performed and the new yielded zone of slope was shown in Figure 4.

In the third reduction calculation, only the strength of the new yielded elements which is obtained at the second elastic-plastic calculation was reduced according to Figure 4, and elasticplastic calculation was conducted. The failure process of the yielded zone is shown in Figure 5 by the local dynamic reduction calculation.

The safety factor $F_{\mathrm{s}}$ that stands for the stability of the slope was calculated by Morgenstern-Price method of limit equilibrium theory. The $F_{\mathrm{s}}$ dropped dynamically (shown in Figure 6). The global safety factor of the slope was 1.31 without reduction, and dropped to 1.1 when the reduction number is 8 . Then, the progressive failure became selfreinforcing and the $F_{\mathrm{s}}$ dropped to less than 1.0, causing a catastrophic acceleration to failure.

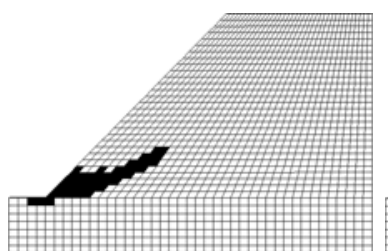

a. $5^{\text {th }}$

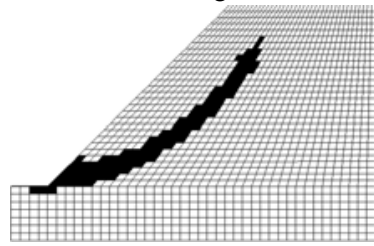

c. 10th

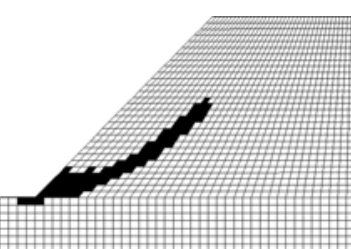

b. 8 th

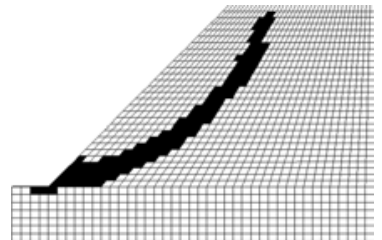

d. 11th
Figure 5 Evolution of yielded zone by local dynamic reduction

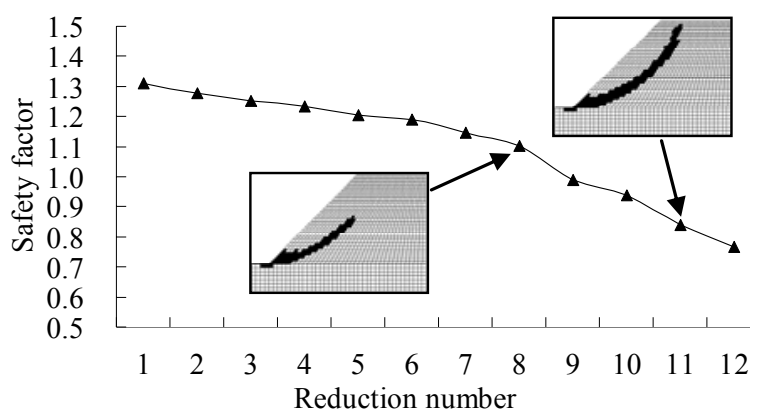

Figure 6 Safety factor curve in the progressive failure

\subsection{Overall strength reduction method}

The traditional overall strength reduction was adopted to analyze the slope, and the strength parameters of all elements of the whole slope were reduced. Figure 7 is the yielded zone distribution during the reduction process. The yielded region firstly appeared at the bottom of the slope (Figure $7 \mathrm{a}$ and Figure $7 \mathrm{~b}$ ), then ran through the bottom area (Figure $7 \mathrm{c}$ ), and extended upward. At last, massive yielded elements occurred in the slope. The result shows that the yielded zone by overall strength reduction is quite different from the actual yielded zone of slope.

\subsection{Advantages of the local dynamic reduction}

Figure 8 shows the deformation vs. Reduction number for Point A (see Figure 3), obtained by using the two kinds of strength reduction methods. At the 12th reduction, the deformation values of 
local and whole reduction are $8.6 \mathrm{~mm}$ and $13.2 \mathrm{~mm}$ respectively. Calculation shows that the overall strength reduction may lead to a greater deformation than the actual value. Therefore, the deformation that obtained by the traditional overall strength reduction can not be used as the early warning index for the stability of slope.

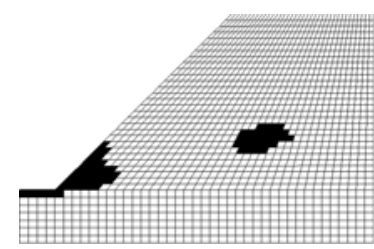

a. $1 \mathrm{st}$

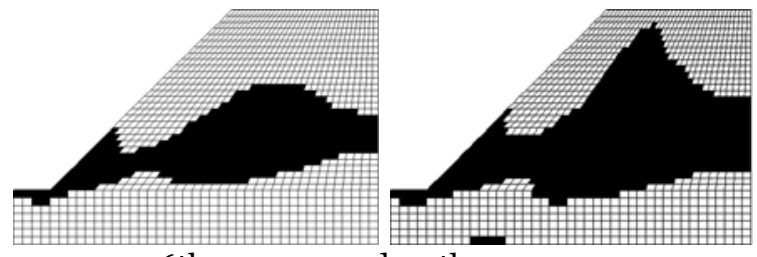

c. 6 th

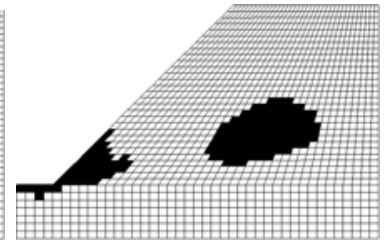

b. $4^{\text {th }}$

d. 9 th
Figure 7 Evolution of yielded zone by overall strength reduction

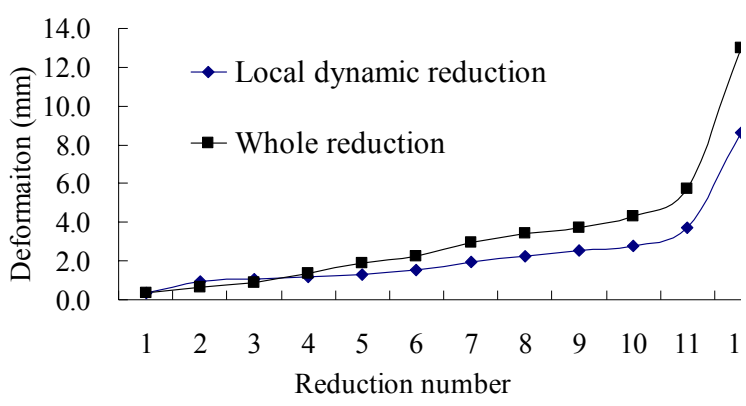

Figure 8 Deformation curves of slope by the two strength reduction methods

As is shown in Figure 5 and Figure 7 , the yielded area obtained by the overall shear strength reduction is much greater than that by the local reduction method. It was difficult to identify the potential sliding surface of the landslide by overall shear strength reduction. Therefore, the yielded zone and sliding surface of the slope can be obtained by using the local dynamic reduction method and the defect of overstated yielded zone caused by the overall reduction can be avoided.

\section{Case study of Heterogeneous Slope}

Not only the above example is a homogeneous slope, but the local dynamic reduction method is also suitable for heterogeneous slope. The Danba landslide is a multi-layers slope, and the actual failure process of the landslide is obtained by the local dynamic reduction method.

\subsection{Characteristic of the landslide}

The Danba landslide is located at the eastern edge of Qinghai-Tibet Plateau, on the right bank of the Dajinhe River in Danba County, Sichuan Province, West China. The potential slide is at the bottom of Baika steep slope, as is illustrated in Figure 9. The geotectonic movement is characterized by a strong uplift of surface and valley undercut. Since the Pliocene, Qinghai-Tibet Plateau has experienced several strong uplifts, the terrain of landslide region is characterized by high altitude and steep slope, with the elevation of 1,887 $\mathrm{m}$ at the toe and 2,110 $\mathrm{m}$ at the top. Its back crack is located at the foreside of grade II platform of Baika Mountain and some bedrock can be found on both sides of the landslide. The average thickness of the landslide is about $30 \mathrm{~m}$ with an area of 0.08 $\mathrm{km}^{2}$ and a volume of about 2.2 million $\mathrm{m}^{3}$. The landslide is an ancient landslide, which is a large accumulated layer landslide.

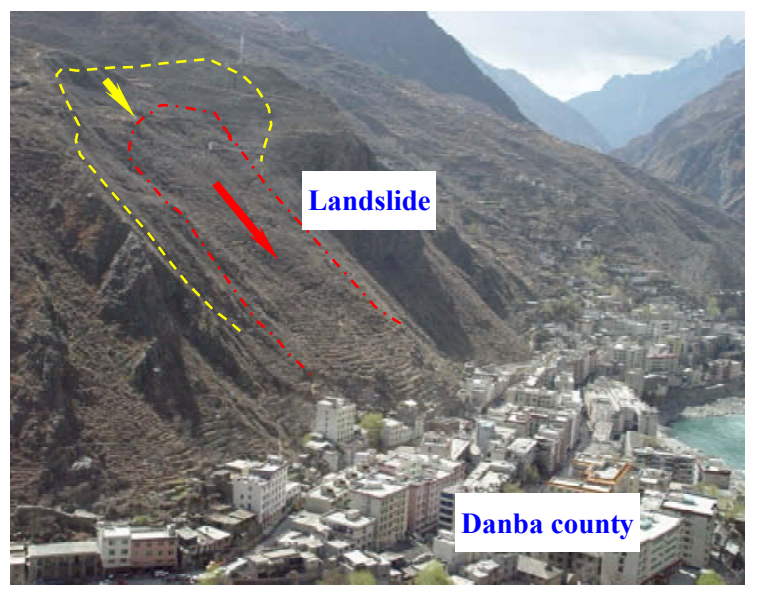

Figure 9 Danba landslide panorama near the county

With the economic development of Danba County, a large number of buildings had been constructed along the toe of slope since 1998. Ongoing excavation have changed the initial stress condition and jeopardized the limit equilibrium state of the slope. From March 2004 to October 2004, intense deformation which is downward the 
free space of the slope took place under the unloading action of the excavation.

The structure of the slope was damaged and became loose, and then shear failure first happened in front of the ancient landslide. Because of the continuous softening of the geomaterial strength, stress re-distribution of the slope body resulted in the failure of deep body gradually. With the development of the intense deformation of slope, sliding surfaces gradually ran down step by step and finally landslide took place.

\subsection{Parameter and numerical model}

A quasi-3D model was established to simulate the failure process of the landslide by using the local dynamic reduction method (Figure 10), with $326 \mathrm{~m}$ in width and $293 \mathrm{~m}$ in height. The model consisted of 9,330 elements and 12,928 nodes. Mohr-Coulomb yield criterion was employed to determine the yielded elements. Displacement constraint was used on both lateral and bottom boundaries, while the surface is set as free.

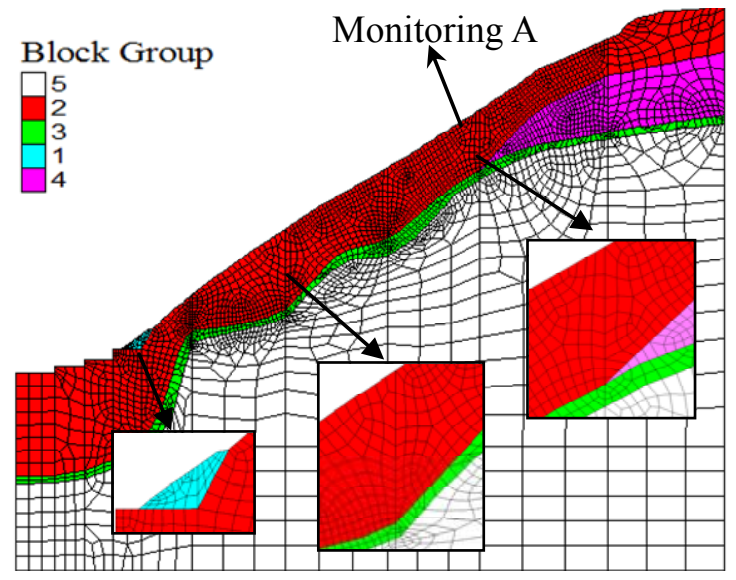

Figure 10 Calculation model of the Danba landslide

The Danba landslide includes five strata, the No.1 of the block group in Figure 10 is the excavation mass because of the construction of new street and building, No.2 is the accumulation mass of the $\mathrm{Q}_{4}$, No.3 is the strong weathering bedrock, No.4 is the ice water stained mass, and No.5 is the bedrock. Because the accumulation mass of the $\mathrm{Q}_{4}$ is the weakest stratum, this layer is the potential slip mass. Therefore, there should be enough and dense meshes in the No.2 body. Danba landslide is considered as heterogeneous, and its strength parameter distribution is shown in Table 1.
Table 1 Mechanical parameters of the Danba landslide

\begin{tabular}{|l|l|l|l|l|l|l|}
\hline NO. & C & FA & D & TS & PR & EM \\
\hline 1 & 64 & 32 & 1,950 & o & 0.33 & 2,000 \\
\hline 2 & 64 & 32 & 1,950 & o & 0.33 & 2,000 \\
\hline 3 & 400 & 45 & 2,230 & 1.0 & 0.30 & 7,200 \\
\hline 4 & 260 & 37 & 2,030 & o & 0.31 & 4,200 \\
\hline 5 & 1,800 & 55 & 2,400 & 1.5 & 0.26 & 11,000 \\
\hline
\end{tabular}

Note: $\mathrm{C}=$ Cohesion $(\mathrm{kPa}) ; \mathrm{FA}=$ Friction angle (degree); $\mathrm{D}=$ Density $\left(\mathrm{kg} / \mathrm{m}^{3}\right) ; \mathrm{TS}=$ Tensile strength $(\mathrm{MPa}) ; \mathrm{PR}=$ Poisson's ratio; $\mathrm{EM}=$ Elastic modulus $(\mathrm{MPa})$

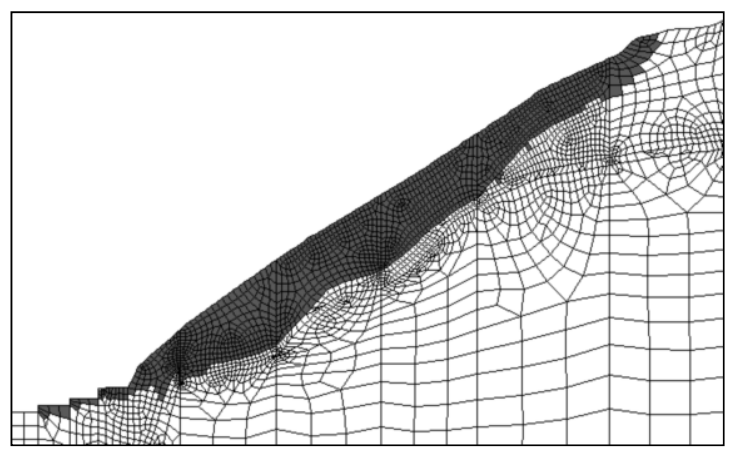

Figure 11 Yielded zone by the overall reduction

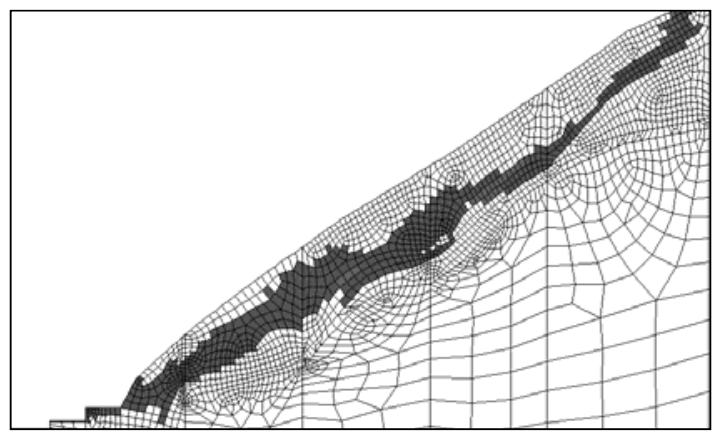

Figure 12 Yielded zone by the local reduction

The yielded zone of the slope by the overall strength reduction is shown as Figure 11, and the yielded zone by the local dynamic reduction method is shown as Figure 12. Progressive failure process of the landslide can be observed from the Figure 13.

At first, the elements of No.1 group in Figure 10 were excavated, and then there was some deformation and yielded zone after the elasticplastic calculation under the gravity. Subsequently, the strength parameter of the yielded elements caused by excavation of the toe of the slope was reduced. The cohesion $C$ was reduced to $0.2 C$. Finally, the elastic-plastic calculation is reperformed and the new yielded zone of slope was 
updated (Figure 13). The result proves that it is possible to simulate the progressive failure of the heterogeneous slope with the local dynamic reduction method.

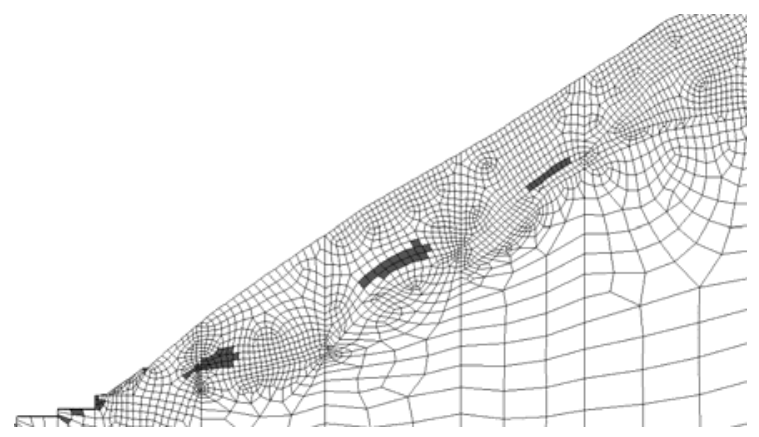

a. after the 2nd reduction

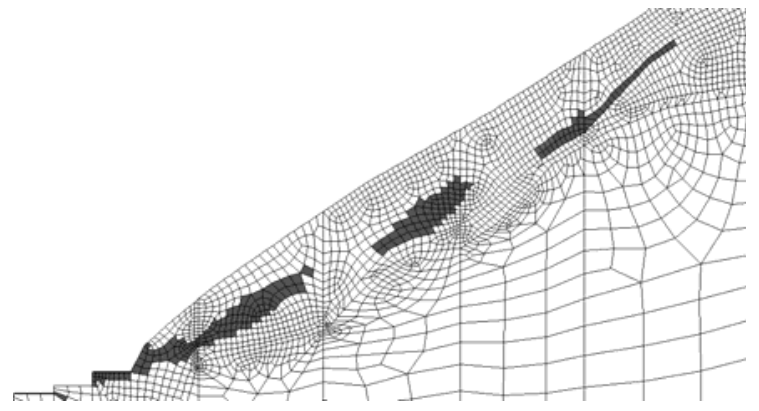

b. after $5^{\text {th }}$ reduction

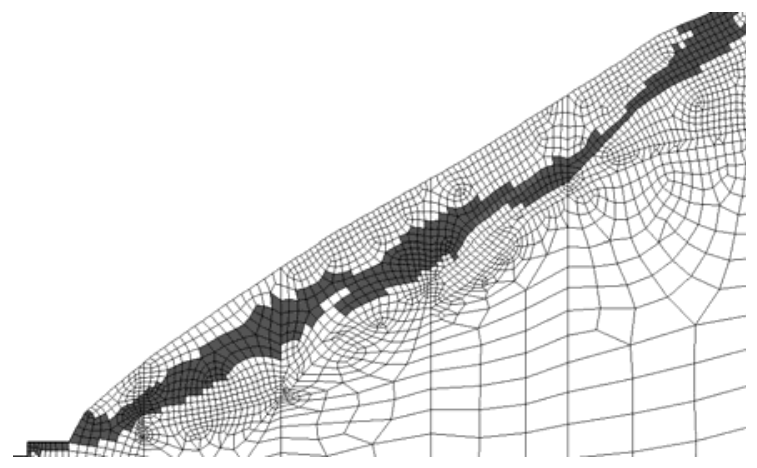

c. after the 1oth reduction

Figure 13 The calculated progressive failure of Danba landslide

As is illustrated in Figure 14, the simulated deformation by the local dynamic reduction method fits well with the monitored results of the landslide. The difference between the measured result and simulated result is small. The result demonstrates that the local dynamic reduction method can accurately reflect the progressive failure of the landslide. The hazard value of the landslide deformation is obtained by using the local dynamic strength reduction. The pre-warning deformation (or hazard value) is $600 \mathrm{~mm}$ corresponding to the mutations point when the reduction number is 13 in Figure 14 . So the mutation in local dynamic strength reduction can provide early warning for the landslide. When deformation value is higher than the "hazard" value, the landslide will slip immediately.

The monitoring deformation of the landslide had been close to the "hazard" value since Feb. 2005 (Figure 15), so the county had been in great danger. If the landslide had taken place instantly, half of the county town would have been destroyed and have endangered more than 4,900 lives in the Danba County. Through the reinforcement stack at the toe of the landslide, anti-slide pile reinforcement and prestressed anchor cable reinforcement, the deformation of the landslide was gradually slowed down in late February, and the landslide was basically at a stable state.

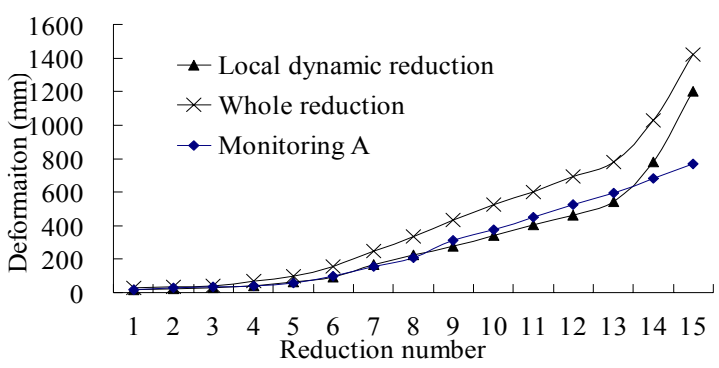

Figure 14 Deformation of point A by reduction method and monitoring

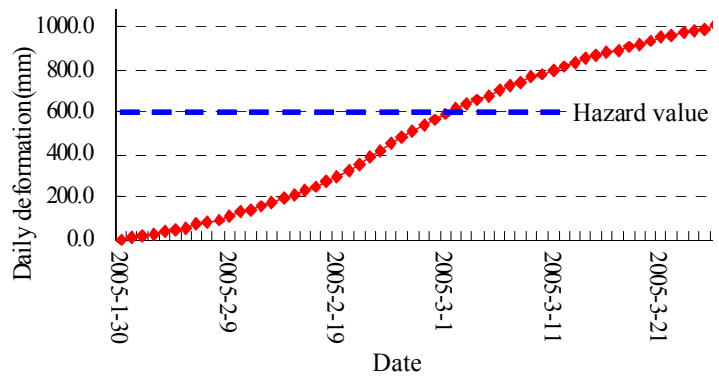

Figure 15 Deformation of the in-situ monitoring at Point A

As is shown in Figure 16, the safety factor $F_{\mathrm{s}}$ of Danba landslide changed dynamically in the process of progressive failure. The global safety factor of the slope was 1.10 without excavation, and dropped to 1.05 when the toe of the slope was excavated. Then the $F_{\mathrm{s}}$ dropped to less than 1.0 because of the softening of the sliding surface, causing a catastrophic acceleration to failure. In 
order to compare the result of the limit equilibrium and the local dynamic reduction, the $F_{\mathrm{s}}$ was calculated with the theory of limit equilibrium after the reinforcement stack was placed and when the reduction number was 10 . The $F_{\mathrm{s}}$ increases slightly based on the theory of limit equilibrium (Figure 16), but the deformation of the landslide decreased obviously. So the deformation is more suitable for the stability evaluation of the landslide than the $F_{\mathrm{s}}$.

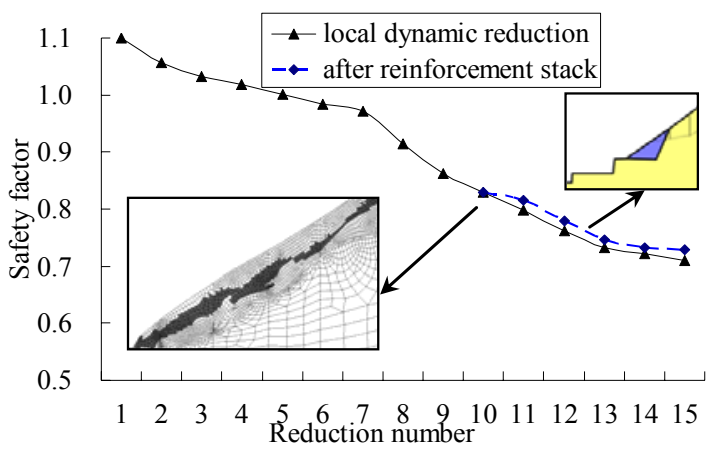

Figure 16 Safety factor variation in the progressive failure

\section{Discussion}

The potential sliding surface of a slope initiates, continuously develops, and cuts through which means the failure state of slope. The evolution process of the yielded zone complies with this feature (Figure 5 and Figure 13). The local dynamic reduction method can overcome aforementioned shortcomings and obtain appropriate yielded zone.

The yielded zone of slope body is not only overstated but also appears in the deep location of slope when the overall strength reduction calculation is used (Zheng et al. 2008). In addition, it is difficult to provide accurate potential sliding surface by the overall strength reduction method.

The theory of limit equilibrium can provide the safety factor of a slope, but it can not simulate the process of progressive failure and deformation of the slope, especially the hazard deformation of the landslide. Most importantly, deformation that obtained from the local dynamic reduction is more suitable for the stability evaluation of the landslide than the $F_{\mathrm{s}}$.

Definitely, the combination of these two methods is a good approach for evaluating slope stability. First, the potential sliding surface of the slope can be searched by the theory of limit equilibrium. Then the meshes which are located at the potential sliding surface must be dense and fine in the numerical model. Finally, a series of $F_{\mathrm{s}}$ are calculated using the theory of limit equilibrium. Therefore, the obtained dynamic $F_{\mathrm{s}}$ is a better alternative to the static $F_{\mathrm{s}}$ in evaluating the slope stability.

The progressive failure of gravity-induced landslide is studied in this paper. However, the local dynamic reduction was inadequate for earthquake or rainfall condition. This method will be further amended and improved in subsequent studies.

\section{Conclusions}

(1) Softening is the main reason that causes landslides. By dynamically reducing the strength of the local yielded zone of the slope, it is possible to search the sliding surface accurately and overcome the shortcoming of over-sized yielded zones caused by the overall strength reduction method.

(2) The overall strength reduction leads to a greater deformation than the actual value, so the warning deformation obtained by the local dynamic strength reduction can provide early warning for landslide.

(3) Two case studies show that local dynamic reduction is not only suitable for homogeneous slope but also for heterogeneous slope.

\section{Acknowledgements}

Thanks to the Cultivating programe of middleaged backbone teachers of Chengdu University of Technology. This work is supported by the National Natural Science Foundation of China (Grant Nos. 41002110, 41272330 and 41130745) and the research fund of State Key Laboratory of Geohazard Prevention and Geoenvironment Protection (Grant No. SKLGP2012Zoo3). This work is also supported by the funding of Science and Technology Office of Sichuan Province (Grant No. 2012JY0110). 


\section{References}

Chemenda AI, Bois T, Bouissou S (2009) Numerical modelling of the gravity-induced destabilization of a slope: The example of the La Clapière landslide, southern France. Geomorphology 109(2): 86-93. DOI: 10.1016/j.geomorph.2009.02.025

Dawson EM, Roth WH, Drescher A (1999) Slope stability analysis by strength reduction. Geotechnique 49(6): 835-840. DOI:10.1680/geot.1999.49.6.835

Eberhardt E, Stead D, Coggan JS (2004) Numerical analysis of initiation and progressive failure in natural rock slopes-the 1991 Randa rockslide. International Journal of Rock Mechanics and Mining Sciences 41(3): 69-87. DOI: 10.1016/S1365-1609(03)00076-5

Eberhardt E, Watson AD, Loew S (2008) Improving the interpretation of slope monitoring and early warning data through better understanding of complex deep-seated landslide failure mechanisms. The 1oth International Symposium on Landslides and Engineered Slopes. Taylor \& Francis Group, London, UK. pp 39-51. DOI: 10.1201/9780203885284-c3

Eberhardt E (2008) Twenty-ninth Canadian Geotechnical Colloquium: The role of advanced numerical methods and geotechnical field measurements in understanding complex deep-seated rock slope failure mechanisms. Canadian Geotechnical Journal 45(4): 484-510. DOI: 10.1139/To7-116

Evans SG, Degraff JV (2002) Catastrophic landslides: effects, occurrence, and mechanisms. The Geological Society of America. pp 30-34

Feng XT, Hudson JA (2010) Specifying the information required for rock mechanics modelling and rock engineering design. International Journal of Rock Mechanics and Mining Sciences 47(2): 179-194. DOI: 10.1016/j.ijrmms.2009.12.009

Giovanni G, Riccardo F, Paolo C, Nicola C (2011) Integration of advanced monitoring and numerical modeling techniques for the complete risk scenario analysis of rockslides: The case of Mt. Beni (Florence, Italy). Engineering Geology 120(1): 48-59. DOI: 10.1016/j.enggeo.2011.03.017

Griffiths DV, Lane PA (1999) Slope stability analysis by finite elements. Géotechnique 49(3): 387-403. DOI: 10.1680/ geot.1999.49.3.387

Li SJ, Gao H, Xu DM (2012) Comprehensive Determination of Reinforcement Parameters for High Cut Slope Based on Intelligent Optimization and Numerical Analysis. Journal of Earth Science 23(2): 233-242. DOI: 10.1007/s12583-012-
0250-9

Leroueil S, Locat A Eberhardt E (2012) Progressive failure in natural and engineered slopes. The 11th International and 2nd North American Symposium on Landslides. Taylor \& Francis Group, London, UK. pp 31-46.

Malet JP, Maquaire O, Calais E (2002) The use of Global Positioning System techniques for the continuous monitoring of landslides: application to the Super-Sauze earthflow (Alpes de Haute Provence, France). Geomorphology 43(1): 33-54. DOI: $10.1016 /$ So169-555X(01)00098-8

Martel SJ (2003) Mechanics of landslide initiation as a shear fracture phenomenon. Marine Geology 203: 319-339. DOI: 10.1016/Soo25-3227(03)oo313-X

Matsui T, San KC (1992) Finite element slope stability analysis by shear strength reduction technique. Soils and Foundations 32(1): 59-70.

Petley DN, Higuchi T, Petley DJ (2005) The development of progressive landslide failure in cohesive materials. Geology 33(3):201-204. DOI:10.1130/G21147.1v.33no.3p.201-204

Rennie B. Kaunda (2010) A linear regression framework for predicting subsurface geometries and displacement rates in deep-seated, slow-moving landslides. Engineering Geology 114(1): 1-9. DOI: 10.1016/j.enggeo.2010.03.004

Saito M (1965) Forecasting the time of occurrence of a slope failure. Proceedings of the 6th International Conference on Soil Mechanics and Foundation Engineering. University of Toronto Press, Canada. pp 537-541.

$\mathrm{Xu} \mathrm{Q}$, Tang MG, Xu KX (2008) Research on space-time evolution laws and early warning-prediction of landslides. Chinese Journal of Rock Mechanics and Engineering 27(6): 1104-1112. (In Chinese)

Yang GH, Zhong ZH, Zhang YC (2010) Slope stability analysis by local strength reduction method. Rock and Soil Mechanics 31(z2): 53-58. (In Chinese)

Zheng H, Liu DF, Li CG (2008) On the assessment of failure in slope stability analysis by the finite element method. Rock Mechanics and Rock Engineering 41(4): 629-639. DOI: 10.1007/soo603-007-0129-8

Zheng H, Sun GH, Liu DF (2009) A practical procedure for searching critical slip surfaces of slopes based on the strength reduction technique. Computers and Geotechnics 36(1): 629639. DOI: 10.1016/j.compgeo.2008.06.002 